\title{
Investigation on the lightning breakdown voltage of palm oil and coconut oil under non- uniform field
}

\begin{abstract}
The increasing interests on the Palm Oil (PO) and Coconut Oil (CO) as a potential alternative for dielectric insulating fluid in transformers encourage a number of researches on different aspects of these oils. Among the common areas under study is the lightning breakdown voltage. In this paper, the lightning breakdown voltage of $\mathrm{PO}$ and $\mathrm{CO}$ is examined. The type of PO used in this study is Refined, Bleached and Deodorized Palm Oil (RBDPO) Olein. The testing was carried out under non-uniform electric field using needle-sphere electrodes configuration. The influence of the testing methods, rising-voltage and up-and-down on the breakdown voltages are investigated for both types of oils. It was found that the lightning breakdown voltage performance for some of the RBDPO is comparable to Mineral Oil (MO).
\end{abstract}

Keyword: Coconut oil; Dielectric insulating fluid; Lightning breakdown voltage; Nonuniform field; Palm oil; Transformers 